\title{
Association between arsenic exposure from drinking water and hematuria: results from the Health Effects of Arsenic Longitudinal Study
}

\author{
Tyler R. McClintock ${ }^{a, b}$, Yu Chen ${ }^{a,{ }^{*}}$, Faruque Parvez ${ }^{c}$, Danil V. Makarov ${ }^{b, d, e, f}$, Wenzhen Ge ${ }^{a}$, \\ Tariqul Islam $^{\mathrm{g}}$, Alauddin Ahmed ${ }^{\mathrm{g}}$, Muhammad Rakibuz-Zaman ${ }^{\mathrm{g}}$, Rabiul Hasan ${ }^{\mathrm{g}}$, Golam \\ Sarwarg, Vesna Slavkovichc, Marc A. Bjurlin ${ }^{\mathrm{b}}$, Joseph H. Grazianoc ${ }^{\mathrm{c}}$, and Habibul Ahsan ${ }^{\mathrm{h}}{ }^{*}$ \\ aDepartments of Population Health and Environmental Medicine, New York University School of \\ Medicine, New York, NY, USA \\ bDepartment of Urology, New York University School of Medicine, New York, NY, USA \\ 'Department of Environmental Health Sciences, Mailman School of Public Health, Columbia \\ University, New York, NY, USA \\ ${ }^{\mathrm{d}}$ Robert F. Wagner Graduate School of Public Service, New York University, New York, NY, USA \\ eUnited States Department of Veterans Affairs Harbor Healthcare System, New York, NY \\ fNew York University Cancer Institute, New York, NY, USA \\ gU-Chicago Research Bangladesh, Ltd., Dhaka, Bangladesh \\ hDepartments of Health Studies, Medicine and Human Genetics and Comprehensive Cancer \\ Center, The University of Chicago, Chicago, IL, USA
}

\section{Abstract}

Arsenic (As) exposure has been associated with both urologic malignancy and renal dysfunction; however, its association with hematuria is unknown. We evaluated the association between drinking water As exposure and hematuria in 7,843 men enrolled in the Health Effects of Arsenic Longitudinal Study (HEALS). Cross-sectional analysis of baseline data was conducted with As exposure assessed in both well water and urinary As measurements, while hematuria was measured using urine dipstick. Prospective analyses with Cox proportional regression models were based on urinary As and dipstick measurements obtained biannually since baseline up to six years. At baseline, urinary As was significantly related to prevalence of hematuria $(P$-trend $<$ 0.01 ), with increasing quintiles of exposure corresponding with respective prevalence odds ratios of 1.00 (reference), 1.29 (95\% CI: 1.04-1.59), 1.41 (95\% CI: 1.15-1.74), 1.46 (95\% CI: 1.19 1.79 ), and 1.56 (95\% CI: 1.27-1.91). Compared to those with relatively little absolute urinary As change during follow-up $(-10.40$ to $41.17 \mu \mathrm{g} / \mathrm{l})$, hazard ratios for hematuria were 0.99 (95\% CI: $0.80-1.22)$ and 0.80 (95\% CI: $0.65-0.99$ ) for those whose urinary As decreased by $>47.49 \mu \mathrm{g} / \mathrm{l}$

\footnotetext{
(C) 2014 Elsevier Inc. All rights reserved.

*Correspondence to: Yu Chen, Department of Population Health, New York University School of Medicine; 650 First Avenue, New York, NY 10016; Eyu.chen@ nyumc.org. Habibul Ahsan, Center for Cancer Epidemiology and Prevention, the University of Chicago; 5841 South Maryland Avenue, Suite N102, Chicago, IL 60637; habib@uchicago.edu.

CONFLICT OF INTEREST

The authors declare that there is no conflict of interest.

Publisher's Disclaimer: This is a PDF file of an unedited manuscript that has been accepted for publication. As a service to our customers we are providing this early version of the manuscript. The manuscript will undergo copyediting, typesetting, and review of the resulting proof before it is published in its final citable form. Please note that during the production process errors may be discovered which could affect the content, and all legal disclaimers that apply to the journal pertain.
} 
and 10.87 to $47.49 \mu \mathrm{g} / \mathrm{l}$ since last visit, respectively, and 1.17 (95\% CI: $0.94-1.45$ ) and 1.36 (95\% CI: 1.10-1.66) for those with between-visit increases of 10.40 to $41.17 \mu \mathrm{g} / \mathrm{l}$ and $>41.17 \mu \mathrm{g} / \mathrm{l}$, respectively. These data indicate a positive association of As exposure with both prevalence and incidence of dipstick hematuria. This exposure effect appears modifiable by short-term changes in drinking water As.

\section{Keywords}

Arsenic; Bangladesh; environmental epidemiology; hematuria; mass screening; urologic neoplasms

\section{INTRODUCTION}

Hematuria is a prevalent clinical finding, experienced by as much as $18 \%$ of the United States population at least once during their lifetime (Grossfeld et al., 2001). As the most common symptom of urinary tract disease, it is associated with a wide array of pathological processes, including glomerular dysfunction, papillary necrosis, urolithiasis, infection, benign prostatic hyperplasia, and malignancy, among others (Cohen and Brown, 2003). As such, the American Urological Association (AUA) best practice policy recommendations for asymptomatic microscopic hematuria were modified in 2012 to advise that, in the absence of a clear etiology, any adult with three or more red blood cells per high powered field on a single urinary specimen should undergo a complete diagnostic evaluation, to include cystoscopy and upper urinary tract imaging (Davis et al., 2012). With hematuria representing an indeterminate clinical presentation for both benign and malignant pathology, more targeted recommendations would rely upon effective identification of risk factors for hematuria-related disease.

Exposure to arsenic (As), a natural element of the Earth's crust and common drinking water contaminant, could play an important role in hematuria prevalence. The presence of this toxic substance in drinking water profoundly impacts human health and is an issue of critical public health importance as more than 200 million persons worldwide may be chronically exposed (Naujokas et al., 2013). In the United States alone, nearly 5\% of the country (13 million individuals) relies on a primary water source with As concentrations exceeding recommended levels (Bissen and Frimmel, 2003). Recent evidence has suggested that As exposure may impair renal function and promote development of renal disease and renal cell carcinoma (Hopenhayn-Rich et al., 1998; Hsueh et al., 2009; Yuan et al., 2010; Huang et al., 2011; Ferreccio et al., 2013). Furthermore, with environmental exposures representing the most important factor in development of urothelial carcinoma (Volanis et al., 2010), As exposure from drinking water has been strongly linked with development of bladder cancer especially at high levels of exposure and among smokers (Chen et al., 1985; Chen et al., 1986; Bates et al., 1995; Kurttio et al., 1999; Marshall et al., 2007; Steinmaus et al., 2013). It is therefore plausible that As may raise incidence of hematuria either by inducing nonmalignant epithelial inflammation and renal dysfunction or, alternatively, through premalignant and malignant processes. Investigating the association between As and hematuria - particularly at low-to-moderate exposure levels - could provide insight on the underlying mechanisms by which As may lead to renal and urothelial disease. To date, however, no studies have examined the relationship between long-term exposure to drinking water As and prevalence of hematuria.

The Health Effects of Arsenic Longitudinal Study (HEALS) provides a unique opportunity to explore the impact of As on hematuria. We established this study in 2000 with 11,746 individuals in Araihazar, Bangladesh, exposed to mean drinking water As of $99 \mu \mathrm{g} / \mathrm{l}$ for an 
average of 8 years (Ahsan et al., 2006b; Chen et al., 2011a). Subsequent As mitigation efforts reduced urinary As levels in some subjects (Chen et al., 2007), thereby providing the opportunity to assess hematuria in the context of longitudinal changes in exposure level. In the present study, we conducted cross-sectional and prospective analyses within male HEALS participants to evaluate the association of As exposure (measured through well and urinary concentrations) with prevalence of dipstick hematuria at baseline and incidence of hematuria during follow-up.

\section{MATERIALS AND METHODS}

\section{Study population}

The HEALS is an ongoing population-based prospective cohort study in Araihazar, Bangladesh that has been previously described (Ahsan et al., 2006a). Between October 2000 and May 2002, we recruited individuals from a well-defined $25 \mathrm{~km}^{2}$ rural geographical area east of the capital city of Dhaka, under the criteria that all were married (to reduce loss to follow-up), between 18-75 years old, and had resided in the study area for at least 5 years. A precohort survey yielded 65,876 individuals in the study area, from which we identified a sampling frame of 14,828 eligible residents. With 2778 members of this sample not home during any of 3 attempted recruiting visits, we ultimately enrolled 11,746 of the remaining 12,050 individuals (97.5\% response rate). From 2006 to 2008, HEALS was expanded to include an additional 8,287 participants ("expansion cohort") following the same methodologies. At each enrollment period, trained study physicians conducted in-home baseline clinical assessments and structured interviews. Active follow-up occurs through inperson assessments that are conducted biennially for each enrollee, following the same procedures used in the baseline interview. Verbal consent was obtained from study participants and the study procedures were approved by the Institutional Review Boards of both Columbia University and University of Chicago, as well as by the Ethical Committee of the Bangladesh Medical Research Council. The present study utilized data collected up to the third follow-up for original cohort members and through the first follow-up visit for the expansion cohort.

Because menstruation status was not recorded at the time of urine collection, the present analysis was limited to male study participants. Of the 8148 total men enrolled in the HEALS during both recruitment periods, 256 were excluded for missing baseline urinary As data and 49 were excluded for missing baseline urine dipstick interpretation. This left 7843 individuals for inclusion in the present study.

\section{Hematuria assessment}

At the time of baseline and each of the follow-up visits, dipstick urinalysis was performed by a trained physician on freshly evacuated spot urine samples collected from the participants using the Chemstrip Micral Test Strips (Roche Diagnostics, USA). The study physicians were blinded to urinary As and well As levels (Ahsan et al., 2006b). The results of the urine test were based on a color scale that quantified hematuria as negative, trace, 50 ery $/ \mu 1$, or 250 ery $/ \mu 1$. In the present study, hematuria was defined as any dipstick finding with trace, $50 \mathrm{ery} / \mu \mathrm{l}$, or $250 \mathrm{ery} / \mu \mathrm{l}$.

\section{Arsenic exposure assessment}

At baseline, water samples from all 10,971 tube wells in the study area were collected. The samples were acidified to $1 \%$ with high-purity Optima hydrochloric acid (Fisher Scientific, Pittsburgh, Pennsylvania) for at least 48 hours before analysis. Total As concentration was analyzed by high-resolution inductively-coupled plasma mass spectrometry with a detection limit of $<0.2 \mu \mathrm{g} / \mathrm{l}$. Detailed information on duration and source of exposure was included 
elsewhere (Ahsan et al., 2006b). As one of the eligibility criteria for the study, all participants were primary user of one of the tested tube wells, designated as the "index" well for at least 3 years. Individuals' choice of well was largely based on geographical convenience, and well As concentration was not well known among the study population before recruitment (Ahsan et al., 2006a). Though previous analysis of a time-series utilizing a subset of 20 tube wells in the study area indicates that the As concentration in well water is relatively stable over time (Cheng et al., 2005), it should be noted that in the original cohort, As mitigation efforts following initiation of the HEALS resulted in over half of those enrollees whose water source was deemed unsafe (based on the national standard of 50 $\mu \mathrm{gAs} / \mathrm{l})$ switching to other wells (Chen et al., 2007).

Urine samples were collected from each participant at baseline as well as during each biennial in-person assessment. All samples were kept in portable coolers immediately after collection. Within 2 to 8 hours, urine samples were processed and transferred to $-20^{\circ} \mathrm{C}$ freezers in the study office located in Dhaka. Samples were kept frozen and shipped to Columbia University on dry ice within 1-2 months. Total urinary As concentration in urine samples collected at baseline and all the follow-up visits were measured by graphite furnace atomic absorption (GFAA) spectrometry, using a Perkin-Elmer Analyst 600 graphite furnace system, as previously described (Nixon et al., 1991). Urinary creatinine was analyzed using a method based on the Jaffe reaction for adjustment of urinary total As concentration (Slot, 1965).

\section{Statistical analysis}

All covariate data were derived from the baseline interview. Sociodemographic factors consisted of age (years), education (years), and smoking status (never, past, or current). Study physicians measured blood pressure with an automatic sphygmomanometer and measured height and weight three times to provide the basis for body mass index (BMI) calculations. For eligible individuals, there were very few missing data on the aforementioned covariates (> 99\% complete).

Initial descriptive analyses compared baseline characteristics in those with and without baseline dipstick hematuria, as well as in participants free of hematuria at baseline who developed incident hematuria during the study period and the subset who did not present with hematuria at any follow-up. We also stratified the study population by interpretation of baseline dipstick urinalysis for hematuria to further describe the overall cohort in terms of variables that included baseline As exposure measurements (water and urinary As).

Logistic regression was conducted to cross-sectionally evaluate the relationship between baseline As exposure and presence of dipstick hematuria, defined as any positive reading (trace, $50 \mathrm{ery} / \mu \mathrm{l}$, or $250 \mathrm{ery} / \mu \mathrm{l}$ ). We estimated prevalence odds ratios (ORs) for hematuria in relation to both well and urinary As in quintiles, adjusting for age, BMI, cigarette smoking status, education length, systolic blood pressure (SBP), diastolic blood pressure (DBP), and occupational dye exposure, which accounts for many literature-reported risk factors for hematuria (Jung et al., 2011; Cha et al., 2012; Loo et al., 2013). Arsenic concentrations measured in spot urine samples may be affected by the variation in dilution due to variation in the state of hydration. Because adjustment of urinary As by creatinine may misestimate exposure in malnourished populations, adjustments were instead made for urinary specific gravity as described and recommended by Nermell et al (Nermell et al., 2008). In this approach, each single urinary As value was adjusted by the respective specific gravity recorded for that sample. Specifically, As was adjusted for the overall mean specific gravity value of 1.013 of the total study group (range, 1.00-1.03), according to: urinary As $\times(1.013$ $-1) /($ measured SG - 1). Additional adjustment for cohort membership (original versus expansion) yielded similar results and, hence, those data are not shown here. 
Prospective analyses for incident hematuria were conducted among the 6654 individuals for whom a negative urine dipstick for hematuria was recorded at baseline. Cox proportional hazard models, which have been employed for previous longitudinal studies of urine dipstick outcomes (Jee et al., 2005; Chen et al., 2011b), were utilized to compare incidence of hematuria across varying levels of baseline water and urinary As. Person-years of followup were calculated for each individual and consisted of the interval between date of baseline visit and either date of incident hematuria or, for those with no recorded hematuria, date of last follow-up. Hazard ratios (HRs) were adjusted for the same potential confounders integrated into the cross-sectional analysis, with age, BMI, cigarette smoking status, education length, systolic blood pressure (SBP), diastolic blood pressure (DBP), and occupational dye exposure treated as time-invariate variables. An additional model also included change in specific gravity-adjusted urinary As since previous visit as a timedependent variable. In cases where individuals did not provide urine samples at the first $(n=470 ; 7.06 \%)$, second $(n=393 ; 10.25 \%)$, or third follow-up visit $(n=514 ; 13.40 \%)$, cohortspecific mean substitution was used for change in urinary As in affected intervals. Sensitivity analyses were conducted limiting prospective analysis to the 5708 individuals with no missing follow-up values (85.78\% of total cohort); results were similar and therefore are not presented here. Additional hazard models were constructed to estimate the HRs for hematuria associated with degree of change in specific gravity adjusted urinary As. Here, visit-to-visit interval changes in the period preceding terminal visit (incident visit for those with hematuria, last follow-up for those without) were divided into five categories, with cut points determined based on quintile values of all data on visit-to-visit change in urinary As, and analyzed as a time-dependent exposure variable in a Cox proportional hazard model that adjusted for potential confounders. To determine any variations in risk modification due to level of baseline exposure, this analysis was repeated, splitting the cohort into two groups: those with below median baseline well As $(43.98 \mu \mathrm{g} / \mathrm{l})$ and those whose baseline well As was equal to or greater than median. All analyses were conducted using SPSS version 20 (SPSS Inc., Chicago, IL).

\section{RESULTS}

Several characteristics of the study population differed by baseline hematuria status, as is shown in Table 1. For example, prevalent cases tended to be older and possess both higher blood pressure and urinary creatinine. Cigarette use was also more common among baseline hematuria cases, with $78.8 \%$ prevalence of past or present smoking (compared with $70.1 \%$ in non-cases; $P<0.01)$. Similar distinctions were seen when non-cases at baseline were divided and analyzed on the basis of subsequent incident hematuria during the study period. Compared with those who did not develop hematuria during follow-up, cases of incident hematuria tended to be older, have higher urinary creatinine, and be more likely to have a history of cigarette smoking $(P<0.01$ for all variables). Appendix Table 1 displays baseline variables by interpretation of dipstick urinalysis for hematuria, where it is noteworthy that both baseline well As and baseline urinary As differ between positive and negative dipstick interpretation $(P<0.01$ for both).

In cross-sectional analysis (shown in Table 2), prevalence of hematuria is shown to increase by quintile of baseline exposure - for example, increasing from $13.2 \%$ in the lowest quartile of water As to $20.1 \%$ in the highest. Corresponding adjusted OR in the fifth quintile of water As showed a $66 \%$ elevated risk relative to the first quartile (OR=1.66; 95\% CI: $1.37-2.02$; $P$-trend $<0.01)$. Similarly, for specific gravity-adjusted urinary As, there was a $6 \%$ increase in OR per SD increase in exposure (SD[specific gravity-adjusted urinary As] $=133.74 \mu \mathrm{g} / \mathrm{l}$; $\mathrm{SD}$ [well As] $=106.08 \mu \mathrm{g} / \mathrm{l})$. This translated to an OR of 1.56 (95\% CI: $1.27-1.91)$ in the fifth urinary As quintile and a significant $P$ for trend.

Toxicol Appl Pharmacol. Author manuscript; available in PMC 2015 April 01. 
Table 3 shows the results of the prospective portion of our analysis, consisting of HRs for incident hematuria during the course of our study period. In the model adjusting for potential confounders (model 1), all exposure variables showed a significant association with risk of incident hematuria, with $P$-trend $<0.01$ for water As and equal to 0.02 for both and urinary As and specific gravity adjusted urinary As. For baseline water As, HRs ranged from 0.96 (95\% CI: 0.77-1.20) in the third quartile to 1.35 (95\% CI: 1.10-1.66) in the fifth quartile. The fifth quartile of specific gravity adjusted urinary As was associated with a $20 \%$ increased risk of incident hematuria ( $\mathrm{HR}=1.20$ [95\% CI $=0.98-1.48])$. In the second model, which included a time-dependent variable for change in urinary As since baseline, baseline well continued to show an association with hematuria incidence $(P<0.01$ and $P=$ 0.05 , respectively), though specific gravity adjusted urinary As did not $(P=0.27)$.

The association between change in urinary As and incident hematuria is illustrated in Figure 1. In the overall cohort, a decrease in urinary As between 10.87 and $47.49 \mu \mathrm{g} / \mathrm{l}$ was associated with a $20 \%$ lower risk of hematuria ( $\mathrm{HR}=0.80$ [95\% CI $=0.65-0.99])$, while an increase of more than $41.17 \mu \mathrm{g} / \mathrm{l}$ corresponded to $36 \%$ higher likelihood of developing hematuria $(\mathrm{HR}=1.36[95 \% \mathrm{CI}=1.10-1.66])$. Separating the population by baseline water As level shows that the trend in HRs may be stronger among those with below median exposure $(P<0.01)$ than in those whose exposure was at or above the median $(P=0.28)$. In the lower exposure group, HRs ranged from 0.82 (95\% CI: $0.58-1.16)$ and 0.80 (95\% CI: $0.60-1.07)$ in the first and second quintiles, respectively, to 1.41 (95\% CI: 1.03-1.92) in the fifth quintile.

\section{DISCUSSION}

To the best of our knowledge, the present study represents the first to investigate an association between As exposure and presence of hematuria. Consistent with our hypothesis, we found a positive association between As and hematuria, both in cross-sectional and prospective analyses. Due to targeted interventions in the study population, As exposure levels in some participants with higher levels of baseline water As changed during the follow-up period, illustrating that increases or decreases in drinking water As were related to corresponding changes in hematuria risk.

One paradoxical finding for risk associated with longitudinal change in urinary As, however, emerged in those who experienced the greatest reduction in exposure. While the group whose exposure decreased to a lesser degree experienced a statistically significant risk reduction (HR $=0.80$ [95\% CI: 0.65-0.99]), the subpopulation with the most drastic change remained at equal risk with the reference group, which experienced little to no change in exposure. We believe a reasonable explanation for this phenomenon is found in the systematic As mitigation efforts within the HEALS (Chen et al., 2007; Madajewicz et al., 2007), as $58 \%$ of those whose primary water source was deemed "unsafe" (As $\geq 50 \mu \mathrm{g} / \mathrm{l}$ ) at enrollment were shown to have switched to wells with As $<50 \mu \mathrm{g} / \mathrm{l}$ two years after interventions had begun. Hence, it is likely that the individuals who experienced the greatest reduction in urinary As consisted of those who had been targeted for well switching because of long term exposure to a high risk well, a notion supported by Figure 1. The lack of risk reduction seen in this subpopulation may signify that their history of high exposure essentially canceled out the effect of As mitigation, at least during the time period that was captured in this study. In this context, it should be noted that those who were most susceptible or at greatest risk (i.e., those who already had hematuria at baseline) were excluded in the prospective analyses, and that the cross-sectional data suggest a more clear dose-response relationship between As exposure and hematuria. 
Prior epidemiologic investigations have reported findings on a positive association between As and subsequent development of renal dysfunction, kidney disease, or urologic malignancy. The seminal ecological studies took place in Taiwan and found the highest levels of As exposure (water As $=800 \mu \mathrm{g} / \mathrm{l}$ ) associated with bladder cancer mortality rate ratios up to 28.7 in men and 65.4 in women when compared with the general population (Chen et al., 1985), while mortality rate ratios for kidney cancer approached 20 and 40 for men and women, respectively (Chen et al., 1988). Dose-response relationships for these cancers have been confirmed through several subsequent studies internationally (IARC, 2004; McClintock et al., 2012; Ferreccio et al., 2013). Beyond malignancy, recent studies from Taiwan and the United States have also related As exposure to increased prevalence of and mortality from renal disease (Lewis et al., 1999; Chiu and Yang, 2005; Meliker et al., 2007; Hsueh et al., 2009). Indeed, it has been suggested that renal disease in exposed populations may be a key intermediate in the eventual development of renal cell carcinoma (Huang et al., 2011). With mortality rates for urothelial and renal malignancies in affected areas having been shown to increase 10 years after onset of exposure and peak more than three decades later, pathological processes involved in malignant transformation are chronic and could conceivably manifest as preclinical hematuria during the latency period (Marshall et al., 2007; Yuan et al., 2010). As a potential indicator of these processes, dipstick hematuria associated with As exposure in the population presented here may conceivably result from non-malignant urothelial irritation, premalignant changes in urothelium, existing urothelial malignancy, or, alternatively, from renal disease. It is likely that some portion of the hematuria observed in this cohort is attributable to renal disease, considering our prior finding of As-associated proteinuria (Chen et al., 2011b). Due to the reversibility of hematuria during the study period, malignancy is a less likely explanation for the majority of our prevalent or incident cases.

Our findings may have implications for the clinical assessment of asymptomatic hematuria, as effective risk stratification enables more selective diagnostic evaluation and informed clinical decisions. Consistent with recognized risk factors, independent predictors of urinary tract cancer in those presenting with asymptomatic hematuria have been found to include male gender, increasing age, greater degree of hematuria (more then 25 red blood cells per high power field), gross hematuria, smoking history, and positive cytology (Jung et al., 2011; Cha et al., 2012; Loo et al., 2013). It has been noted, however, that the accuracy of clinical decision tools based on these parameters would be improved by inclusion of occupational or chemical exposures (Cha et al., 2012). Hence, while not likely to be of significant clinical relevance on their own, we believe the results presented here, along with prior evidence of the association between As and urologic malignancy, illustrate the impact of As exposure on hematuria and underscore the value of integrating this exposure variable into any future decision-making tools in affected populations. Furthermore, given that individuals presenting with hematuria may be more likely to develop subsequent urologic disease or malignancy, hematuria could serve as an early marker of toxicity in surveillance programs to capture As-exposed individuals who may require further follow-up, As mitigation, and evaluation for As toxicity. Such surveillance programs or improved risk stratification would be of particular utility in developing countries, where healthcare resources are limited.

Strengths of the present study include individual-level exposure data obtained at multiple encounters, use of both cross-sectional and prospective analyses, a wide range of As exposure in the population, and an intervention allowing for the effect of exposure mitigation to be analyzed. Certain limitations must also be addressed, including the lack of information on menstruation status requiring that our analyses be restricted to men. We also recognize that reliance on dipstick hematuria rather than microscopic urinalysis limits specificity as hemoglobinuria, myoglobinuria, concentrated urine, and strenuous physical 
activity can all yield false positives on dipstick urinalysis. Limited clinical information was available for study participants, hence we could not control for other renal or urologic disease (infection, urolithiasis, or benign prostatic hyperplasia, among other causes). Similarly, serum creatinine, blood urea nitrogen, and urine cytology were not available for analysis, nor were urinary markers of bladder malignancy. Lastly, we could not fully define the latency of the association. The stronger association seen with water As when it is considered as a continuous variable may result from that marker more accurately capturing long-term exposure in the remote past. On the other hand, urinary As may be more representative of the internal dose of As exposure and thus capture more data variability in recent exposure. Given the lack of a clear dose-response relationship between As exposure and hematuria in prospective analyses, it is conceivable that threshold effects may be limited to a certain follow-up time.

In conclusion, we have found that exposure to As in drinking water is associated with prevalence and incidence of hematuria in this male population with a wide range of exposure. In this first study to explore the association between As and hematuria, we have also shown that decreasing As intake among those with mild to moderate exposure is associated with decreased incidence of subsequent hematuria. It should be noted, however, that risk reduction might not be as immediate or significant in individuals with longer term, higher-level exposure. Given these findings, it is conceivable that As-related hematuria may represent an early, modifiable sign of adverse effects on the urinary system. Future correlation of As-related hematuria with clinical diagnoses and mortality data are needed to further define this relationship and inform population-level screening and diagnostic guidelines.

\section{Acknowledgments}

The authors thank the dedicated project staff and field workers in Bangladesh, without whom this work would not have been possible.

This work was supported by the National Institutes of Health (grants R01 ES017541, R01 CA107431, P42 ES010349, and P30 ES000260) and in part by grant UL1 TR000038 from the National Center for the Advancement of Translational Science (NCATS), National Institutes of Health.

\section{Abbreviations}

As arsenic

HEALS Health Effects of Arsenic Longitudinal Study

\section{References}

Ahsan H, Chen Y, Parvez F, Argos M, Hussain AI, Momotaj H, Levy D, van Geen A, Howe G, Graziano J. Health Effects of Arsenic Longitudinal Study (HEALS): description of a multidisciplinary epidemiologic investigation. J Expo Sci Environ Epidemiol. 2006a; 16:191-205. [PubMed: 16160703]

Ahsan H, Chen Y, Parvez F, Zablotska L, Argos M, Hussain I, Momotaj H, Levy D, Cheng Z, Slavkovich V, van Geen A, Howe GR, Graziano JH. Arsenic exposure from drinking water and risk of premalignant skin lesions in Bangladesh: baseline results from the Health Effects of Arsenic Longitudinal Study. Am J Epidemiol. 2006b; 163:1138-1148. [PubMed: 16624965]

Bates MN, Smith AH, Cantor KP. Case-control study of bladder cancer and arsenic in drinking water. Am J Epidemiol. 1995; 141:523-530. [PubMed: 7900719]

Bissen M, Frimmel FH. Arsenic - a review. Part II: Oxidation of arsenic and its removal in water treatment. Acta Hydroch Hydrob. 2003; 31:97-107. 
Cha EK, Tirsar LA, Schwentner C, Hennenlotter J, Christos PJ, Stenzl A, Mian C, Martini T, Pycha A, Shariat SF, Schmitz-Drager BJ. Accurate risk assessment of patients with asymptomatic hematuria for the presence of bladder cancer. World journal of urology. 2012; 30:847-852. [PubMed: 23124847]

Chen CJ, Chuang YC, Lin TM, Wu HY. Malignant neoplasms among residents of a blackfoot diseaseendemic area in Taiwan: high-arsenic artesian well water and cancers. Cancer Res. 1985; 45:58955899. [PubMed: 4053060]

Chen CJ, Chuang YC, You SL, Lin TM, Wu HY. A retrospective study on malignant neoplasms of bladder, lung and liver in blackfoot disease endemic area in Taiwan. British journal of cancer. 1986; 53:399-405. [PubMed: 3964542]

Chen CJ, Kuo TL, Wu MM. Arsenic and cancers. Lancet. 1988; 1:414-415. [PubMed: 2893213]

Chen Y, Graziano JH, Parvez F, Liu M, Slavkovich V, Kalra T, Argos M, Islam T, Ahmed A, Rakibuz-Zaman M, Hasan R, Sarwar G, Levy D, van Geen A, Ahsan H. Arsenic exposure from drinking water and mortality from cardiovascular disease in Bangladesh: prospective cohort study. BMJ. 2011a; 342:d2431. [PubMed: 21546419]

Chen Y, Parvez F, Liu M, Pesola GR, Gamble MV, Slavkovich V, Islam T, Ahmed A, Hasan R, Graziano JH, Ahsan H. Association between arsenic exposure from drinking water and proteinuria: results from the Health Effects of Arsenic Longitudinal Study. Int J Epidemiol. 2011b; 40:828-835. [PubMed: 21343184]

Chen Y, van Geen A, Graziano JH, Pfaff A, Madajewicz M, Parvez F, Hussain AZMI, Slavkovich V, Islam T, Ahsan H. Reduction in urinary arsenic levels in response to arsenic mitigation efforts in Araihazar, Bangladesh. Environ Health Persp. 2007; 115:917-923.

Cheng Z, van Geen A, Seddique AA, Ahmed KM. Limited temporal variability of arsenic concentrations in 20 wells monitored for 3 years in Araihazar, Bangladesh. Environ Sci Technol. 2005; 39:4759-4766. [PubMed: 16053073]

Chiu HF, Yang CY. Decreasing trend in renal disease mortality after cessation from arsenic exposure in a previous arseniasis-endemic area in southwestern Taiwan. J Toxicol Environ Health A. 2005; 68:319-327. [PubMed: 15799625]

Cohen RA, Brown RS. Clinical practice. Microscopic hematuria. N Engl J Med. 2003; 348:23302338. [PubMed: 12788998]

Davis R, Jones JS, Barocas DA, Castle EP, Lang EK, Leveillee RJ, Messing EM, Miller SD, Peterson AC, Turk TM, Weitzel W. Diagnosis, evaluation and follow-up of asymptomatic microhematuria $(\mathrm{AMH})$ in adults: AUA guideline. The Journal of urology. 2012; 188:2473-2481. [PubMed: 23098784]

Ferreccio C, Smith AH, Duran V, Barlaro T, Benitez H, Valdes R, Aguirre JJ, Moore LE, Acevedo J, Vasquez MI, Perez L, Yuan Y, Liaw J, Cantor KP, Steinmaus C. Case-Control Study of Arsenic in Drinking Water and Kidney Cancer in Uniquely Exposed Northern Chile. Am J Epidemiol. 2013

Grossfeld GD, Litwin MS, Wolf JS, Hricak H, Shuler CL, Agerter DC, Carroll PR. Evaluation of asymptomatic microscopic hematuria in adults: the American Urological Association best practice policy--part I: definition, detection, prevalence, and etiology. Urology. 2001; 57:599-603. [PubMed: 11306356]

Hopenhayn-Rich C, Biggs ML, Smith AH. Lung and kidney cancer mortality associated with arsenic in drinking water in Cordoba, Argentina. Int J Epidemiol. 1998; 27:561-569. [PubMed: 9758107]

Hsueh YM, Chung CJ, Shiue HS, Chen JB, Chiang SS, Yang MH, Tai CW, Su CT. Urinary arsenic species and CKD in a Taiwanese population: a case-control study. American journal of kidney diseases : the official journal of the National Kidney Foundation. 2009; 54:859-870. [PubMed: 19682779]

Huang CY, Chu JS, Pu YS, Yang HY, Wu CC, Chung CJ, Hsueh YM. Effect of urinary total arsenic level and estimated glomerular filtration rate on the risk of renal cell carcinoma in a low arsenic exposure area. The Journal of urology. 2011; 185:2040-2044. [PubMed: 21496841]

IARC. Some drinking-water disinfectants and contaminants, including arsenic. IARC monographs on the evaluation of carcinogenic risks to humans/World Health Organization, International Agency for Research on Cancer. 2004; 84:1-477. 
Jee SH, Boulware LE, Guallar E, Suh I, Appel LJ, Miller ER 3rd. Direct, progressive association of cardiovascular risk factors with incident proteinuria: results from the Korea Medical Insurance Corporation (KMIC) study. Arch Intern Med. 2005; 165:2299-2304. [PubMed: 16246998]

Jung H, Gleason JM, Loo RK, Patel HS, Slezak JM, Jacobsen SJ. Association of hematuria on microscopic urinalysis and risk of urinary tract cancer. The Journal of urology. 2011; 185:16981703. [PubMed: 21419446]

Kurttio P, Pukkala E, Kahelin H, Auvinen A, Pekkanen J. Arsenic concentrations in well water and risk of bladder and kidney cancer in Finland. Environ Health Perspect. 1999; 107:705-710. [PubMed: 10464069]

Lewis DR, Southwick JW, Ouellet-Hellstrom R, Rench J, Calderon RL. Drinking water arsenic in Utah: A cohort mortality study. Environ Health Perspect. 1999; 107:359-365. [PubMed: 10210691]

Loo RK, Lieberman SF, Slezak JM, Landa HM, Mariani AJ, Nicolaisen G, Aspera AM, Jacobsen SJ. Stratifying risk of urinary tract malignant tumors in patients with asymptomatic microscopic hematuria. Mayo Clin Proc. 2013; 88:129-138. [PubMed: 23312369]

Madajewicz M, Pfaff A, van Geen A, Graziano J, Hussein I, Momotaj H, Sylvi R, Ahsan H. Can information alone change behavior? Response to arsenic contamination of groundwater in Bangladesh. J Dev Econ. 2007; 84:731-754.

Marshall G, Ferreccio C, Yuan Y, Bates MN, Steinmaus C, Selvin S, Liaw J, Smith AH. Fifty-year study of lung and bladder cancer mortality in Chile related to arsenic in drinking water. J Natl Cancer Inst. 2007; 99:920-928. [PubMed: 17565158]

McClintock TR, Chen Y, Bundschuh J, Oliver JT, Navoni J, Olmos V, Lepori EV, Ahsan H, Parvez F. Arsenic exposure in Latin America: biomarkers, risk assessments and related health effects. Sci Total Environ. 2012; 429:76-91. [PubMed: 22119448]

Meliker JR, Wahl RL, Cameron LL, Nriagu JO. Arsenic in drinking water and cerebrovascular disease, diabetes mellitus, and kidney disease in Michigan: a standardized mortality ratio analysis. Environmental health : a global access science source. 2007; 6:4. [PubMed: 17274811]

Naujokas MF, Anderson B, Ahsan H, Aposhian HV, Graziano JH, Thompson C, Suk WA. The broad scope of health effects from chronic arsenic exposure: update on a worldwide public health problem. Environ Health Perspect. 2013; 121:295-302. [PubMed: 23458756]

Nermell B, Lindberg AL, Rahman M, Berglund M, Persson LA, El Arifeen S, Vahter M. Urinary arsenic concentration adjustment factors and malnutrition. Environ Res. 2008; 106:212-218. [PubMed: 17900556]

Nixon DE, Mussmann GV, Eckdahl SJ, Moyer TP. Total arsenic in urine: palladium-persulfate vs nickel as a matrix modifier for graphite furnace atomic absorption spectrophotometry. Clinical chemistry. 1991; 37:1575-1579. [PubMed: 1893592]

Slot C. Plasma creatinine determination. A new and specific Jaffe reaction method. Scandinavian journal of clinical and laboratory investigation. 1965; 17:381-387. [PubMed: 5838275]

Steinmaus CM, Ferreccio C, Acevedo Romo J, Yuan Y, Cortes S, Marshall G, Moore LE, Balmes JR, Liaw J, Golden T, Smith AH. Drinking water arsenic in northern Chile: high cancer risks 40 years after exposure cessation. Cancer Epidemiol Biomarkers Prev. 2013

Volanis D, Kadiyska T, Galanis A, Delakas D, Logotheti S, Zoumpourlis V. Environmental factors and genetic susceptibility promote urinary bladder cancer. Toxicol Lett. 2010; 193:131-137. [PubMed: 20051252]

Yuan Y, Marshall G, Ferreccio C, Steinmaus C, Liaw J, Bates M, Smith AH. Kidney cancer mortality: fifty-year latency patterns related to arsenic exposure. Epidemiology. 2010; 21:103-108.

[PubMed: 20010213] 


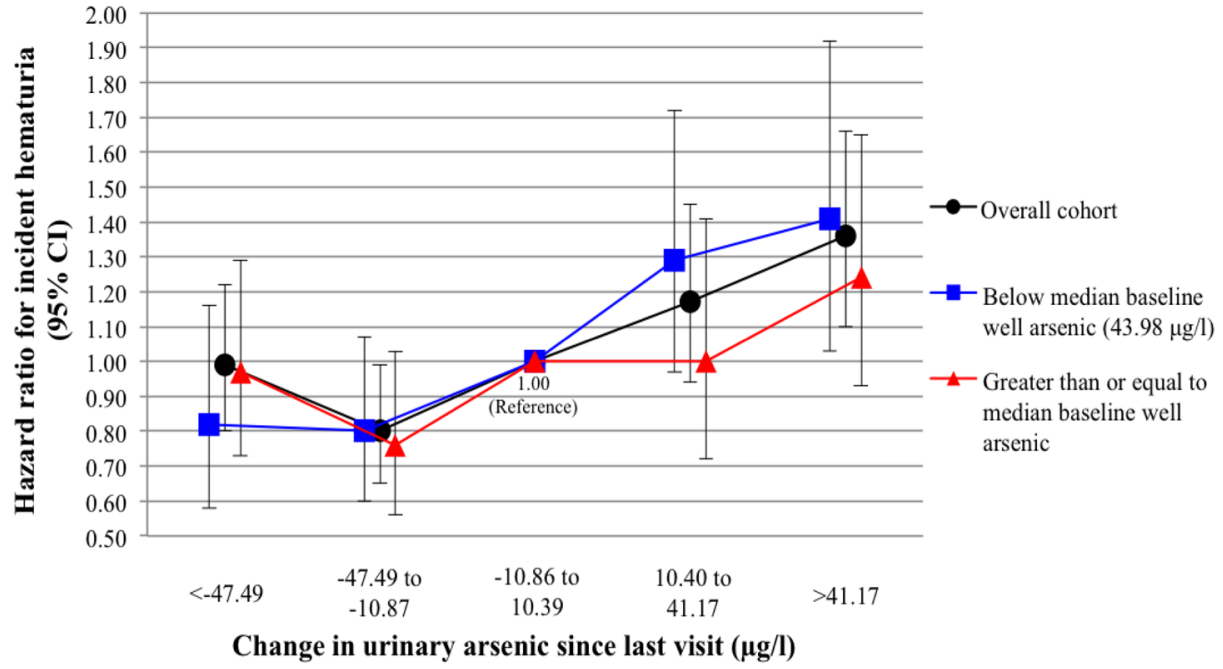

$\begin{array}{cccccc}n & 207 & 194 & 164 & 167 & 217 \\ \begin{array}{c}\text { Follow-up } \\ \text { (person-years) }\end{array} & 5782.44 & 6559.15 & 4571.75 & 4082.75 & 4733.03\end{array}$

Figure 1.

Hazard ratios for incident hematuria according to change in urinary arsenic since last visit 


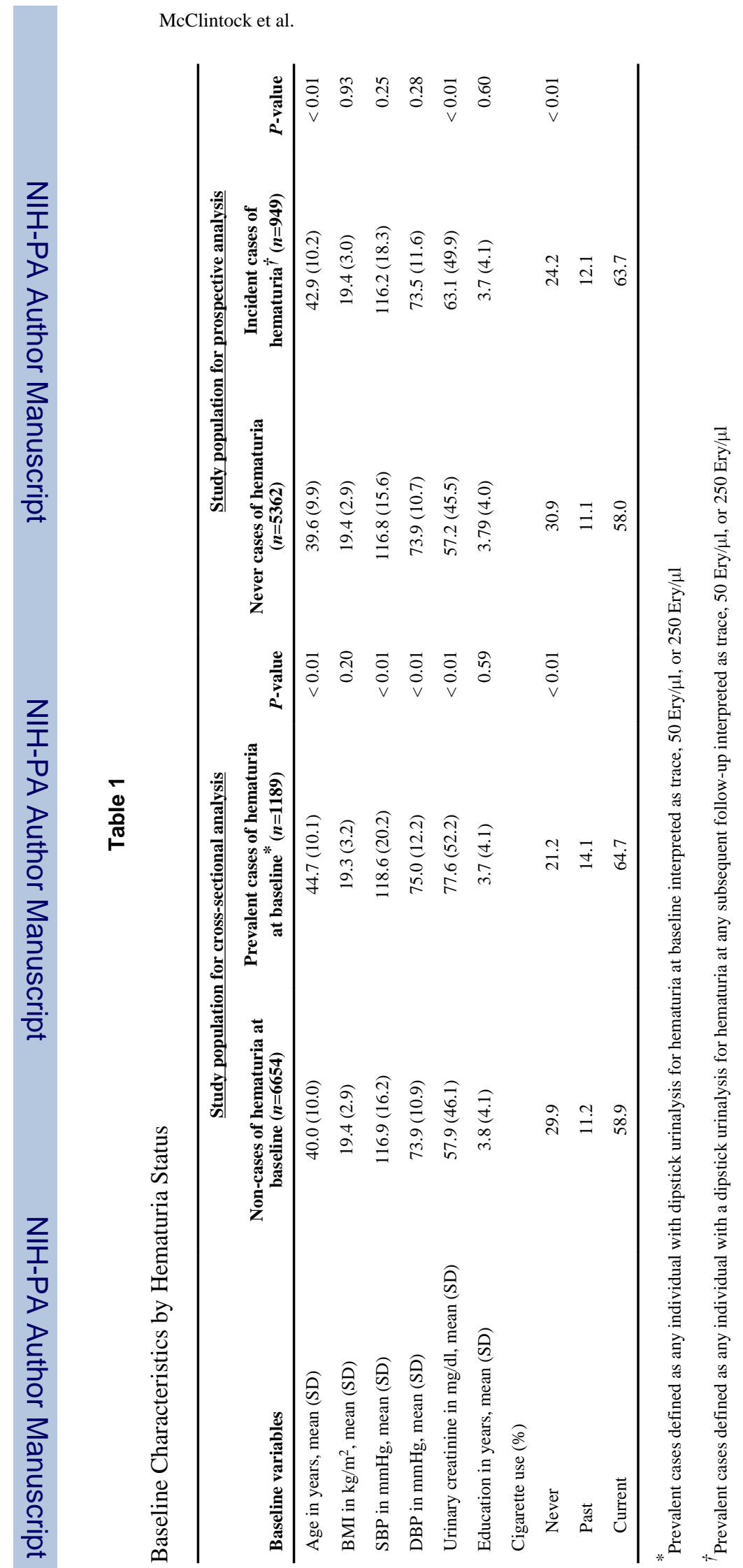

Toxicol Appl Pharmacol. Author manuscript; available in PMC 2015 April 01. 
Table 2

Cross-sectional Analysis of Associations Between Arsenic Exposure and Hematuria at Baseline

\begin{tabular}{|c|c|c|c|}
\hline As exposure variables* & $\begin{array}{l}\text { Prevalence of hematuria in } \\
\%, n \text { (yes/no) }\end{array}$ & $\begin{array}{l}\text { Unadjusted OR }(95 \% \mathrm{CI}) \\
\text { for hematuria }\end{array}$ & $\begin{array}{l}\text { Adjusted OR }(95 \% \text { CI }) \text { for } \\
\text { hematuria }^{\dagger}\end{array}$ \\
\hline \multicolumn{4}{|l|}{ Baseline well As $(\mu \mathrm{g} / \mathrm{l})$} \\
\hline $0.1-3^{*}$ & $13.2(212 / 1399)$ & 1.00 (Ref) & 1.00 (Ref) \\
\hline $3-25$ & $13.7(214 / 1345)$ & $1.05(0.86-1.29)$ & $1.07(0.87-1.31)$ \\
\hline $25-66$ & $12.4(194 / 1365)$ & $0.94(0.76-1.16)$ & $0.95(0.76-1.17)$ \\
\hline $66-142$ & $16.4(254 / 1292)$ & $1.30(1.07-1.58)$ & $1.30(1.06-1.59)$ \\
\hline $142-949.1$ & $20.1(315 / 1253)$ & $1.66(1.37-2.01)$ & $1.66(1.37-2.02)$ \\
\hline $\begin{array}{l}\text { OR per SD increase in exposure } \\
\text { variable }\end{array}$ & & $1.20(1.14-1.27)$ & $1.20(1.13-1.27)$ \\
\hline$P$-value for trend & & $<0.01$ & $<0.01$ \\
\hline \multicolumn{4}{|c|}{ Baseline specific gravity-adjusted urinary As $(\mu \mathrm{g} / \mathrm{l})$} \\
\hline $1.7-39^{*}$ & $11.7(188 / 1414)$ & 1.00 (Ref) & 1.00 (Ref) \\
\hline $39-65$ & $14.6(221 / 1293)$ & $1.29(1.04-1.58)$ & $1.29(1.04-1.59)$ \\
\hline $65-106$ & $16.1(255 / 1331)$ & $1.44(1.18-1.77)$ & $1.41(1.15-1.74)$ \\
\hline $106-179.4$ & $16.5(258 / 1307)$ & $1.49(1.21-1.82)$ & $1.46(1.19-1.79)$ \\
\hline $179.4-2334.8$ & $17.0(266 / 1300)$ & $1.54(1.26-1.88)$ & $1.56(1.27-1.91)$ \\
\hline $\begin{array}{l}\text { OR per SD increase in exposure } \\
\text { variable }\end{array}$ & & $1.06(1.00-1.12)$ & $1.06(1.00-1.13)$ \\
\hline$P$-value for trend & & 0.049 & 0.047 \\
\hline
\end{tabular}

* Cut points determined by quintiles of overall study population at baseline.

${ }^{\dagger}$ ORs adjusted for age, BMI, cigarette smoking status, education length, SBP, DBP, and occupational dye exposure.

Reference group. 
Table 3

Prospective Analysis of Associations Between Arsenic Exposure and Incident Hematuria at Follow-up

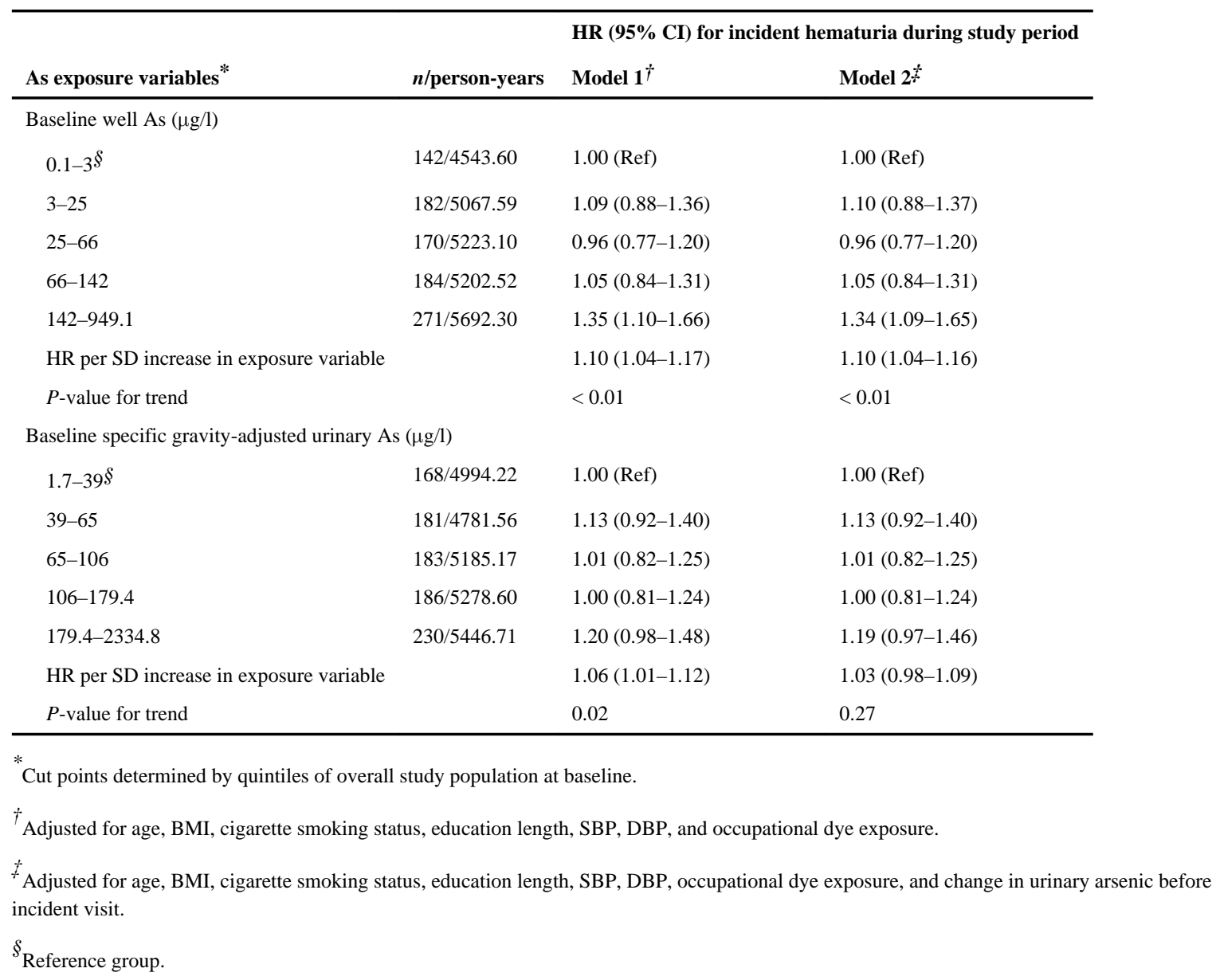


